\title{
Gamification of The Future: An Experiment on Gamifying Education of Forecasting
}

\author{
Nikoletta Zampeta Legaki \\ National Technical \\ University of Athens \\ zabbeta@fsu.gr
}

\author{
Nannan Xi \\ Gamification Group \\ University of Turku \\ nannan.xi@tut.fi
}

\author{
Juho Hamari \\ Gamification Group \\ Tampere University \\ juho.hamari@tut.fi
}

\author{
Vassilios Assimakopoulos \\ National Technical \\ University of Athens \\ vassim@fsu.gr
}

\begin{abstract}
In this study, we developed a gamified learning platform called F-LauReL ${ }^{x p}$ that employed three gamification strategies (called Horses for Courses, JudgeIt and Metrics to Escape) to help educate statistical, judgmental forecasting and forecasting accuracy respectively. This study presents a quantitative analysis of experimental design concerning learning performance of 261 students of an undergraduate and an MBA course. Treatment and control groups were compared in a series of experiments. The results show that using gamified applications as a complementary teaching tool in a forecasting course had a positive impact on students' learning performance.
\end{abstract}

\section{Introduction}

Gamification has become an increasingly adopted technique to affect people's behavior and cognitive process by affording similar experiences as games do [22]. In this respect, there is an increasing interest from both academics and practitioners in using game components in educational process either at university courses, on-line courses or even at business trainings for motivation and amelioration of learning outcomes. In fact, gamification has been especially employed in the domains where people have difficulty of adopting a long-term view and motivational persistence such as education, healthcare, work environments and crowdsourcing $[26,32,34,39]$. One such domain is the education of forecasting which combines both the education realms as well as the long-term perspective.

Predictive analytics are a new trend and in high demand nowadays, principally with the help of the growing computers storage and process power. Additionally, the deep-rooted human desire to predict future events in order to plan their actions is unquestionable. Forecasting techniques help to predict future trends and estimate future values of variables under examination, based on past and present data. Hereof it has been considered as a vital addition in economic curriculum [29], even in undergraduate level [16]. However, approximately only half of Business schools offer forecasting courses because of its complexity [19].

However, thus far there has been a dearth of studies on gamification in the area of forecasting. The studies that touch gamification in this domain have only used score [10], spreadsheets [15] and real-world forecasting problems $[16,5]$ to motivate students' participation.

Therefore, the present study examines the effect of gamification on learning (forecasting techniques comprehension) in forecasting education by conducting a series of experiments employing three different gamification implementations (called Horses for Courses, JudgeIt and Metrics to Escape, respectively). In our experiment, we focus on examining the impact of different tasks such as: reading, use of gamified applications and their combination in students' performance along with the respective performance of the control group. The experiment spanned over one and a half years, and the total sample is composed of 261 undergraduate and MBA students of Electrical and Computer Engineering School of the National Technical University of Athens.

\section{Literature Review}

\subsection{Gamification in education}

Over the last decade, there has been a tremendous increase in literature about gamification in a variety of sectors, principally in education $[18,25,32,39]$. Prior research shows promising outcomes from gamifying education, from elementary school level [11] up to higher education and business training. Popularity of gamification in teaching is based on its potential to engage students, as it happens in the case of game users [40], and motivate them to participate in courses [5]. Based on the literature review of [25], the majority 
of published papers around education and the new gamified concept aim to affect students' motivation, which is affiliated with positive impact on learning. In this regard, a review of gamified projects and webbased platforms with game elements accentuates gamification contribution to classical education [31]. Kuo and Chuang [27] showed that gamification is helpful for the dissemination of academic content as well. Game elements most commonly embodied in educational gamified applications are points, levels and badges [36, 18]. Rules, rewards, quick feedback and competitiveness have been used also, in gamified contexts to induce positive learning outcomes [5].

Despite the fact that gamification in a serious context, such as education, is a promising trend with great potential in teaching and lecture attendance [24], there remain gaps in our understanding of its effects. Gamification's effects are interwoven with the respective target group and environment [18, 6]. Hence, the results of gamification vary [38] and may have positive or no impact on the educational process in the short run [20]. Nevertheless, research, regarding the acceptance of gamification in education, agrees upon the need for more experimental results supported by statistical analysis $[20,6,31,34]$ as there is a lack of empirical data analysis regarding gamification's implementation in the teaching process.

\subsection{Teaching forecasting}

Since, forecasting is an essential topic of management science, supporting decision making activities [41, 33], it has been considered as an important part of an economic and business curriculum $[29,16]$. Nevertheless, usually forecasting courses are not attractive neither to business schools' curriculums $[29,19]$ nor to students, probably due to their complexity [1]. Gapp and Fisher [14] emphasize the lack of students' engagement in their academic activities in management courses that discourage them to reach their full learning potential. In this direction, forecasting courses, usually considered as part of management or economic syllabuses [33], follow more the rule than the exception regarding students' reluctance.

Initiatives and active learning exercises have been proposed in a business forecasting course trying to update the content of the course and make students more active and motivated in their learning [9]. However, the pedagogical perspective has been highlighted by this research, without experimental results regarding the learning outcomes. Furthermore, teaching guidelines and initiatives have been proposed as an effort to ameliorate forecasting teaching, learning [29, 30] and attract students' attention. Improving lectures and teaching processes with information technology and real events exercises are some of the teaching guidelines with published positive impact on students' motivation. Moreover, virtual environments are a catalyst for students' participation in management courses [14]. Last but not least, a prediction market has been used as a pedagogical tool during management courses [7, 5], producing real case decision scenarios. Students were intrigued to search more information about the problem under examination and they were able to apply this gained knowledge more effectively [7]. Hence, active learning and information technology may perform as a force to magnetize students' interest in management and forecasting courses.

\subsection{Gamification in teaching forecasting}

In this direction, we reviewed journal articles about forecasting courses that incorporate active learning events or innovative educational methods. Some effective examples of active learning proposed in the context of a forecasting course are: the use of score during the lectures [10], the ad - hoc use of spreadsheets [15] and the adoption of competition between teachers and students [41]. Another in-class active learning exercise, which appeared beneficial, was the use of a real-world forecasting problem such as the forecast of the points scored by the university basketball team [16]. During the lectures, students were trying to forecast accurately the scored points in the next basketball game. Thus, they were motivated to learn about time series components, and how to use the forecasting methods in order to increase their forecasting accuracy. In this regard, active learning exercises, involving game elements to motivate users, are fruitful for teaching statistical forecasting methods.

Furthermore, forecasting per se has been used as an active learning exercise to arouse students' interest in management courses. Buckley et al. [7] triggered students' active participation, using a prediction market to build decision scenarios based on real facts, during an undergraduate course in risk management. The use of a prediction market in a course could be considered as a useful pedagogical tool that gives active character to education as well [5]. Since the application of a prediction market is accompanied by objective rules, feedback and competition among learners, Buckley and Doyle [5] portrayed a gamified learning experience in a taxation course, with positive impact on students' knowledge level. Forecasting is a kind of art rather than a scientific field [16], thus it can be considered as a fertile ground for applying gamification strategies [5], in order to help students to study on their own initiative and further increase learning outcomes. 
Literature review conducted shows the positive effects of gamification on education based on reviews and empirical literature. Additionally, the overview of teaching forecasting shows that forecasting courses are significant in an economic [29] and undergraduate business curriculum [716], in terms of decision making improvement, but they are not supported by students and business schools' programming [41, 1], as it should be. Focusing on this problem, active learning activities using game elements to motivate students, present promising results in management courses $[5$, $10,41,15]$ and in forecasting module [16]. However, thus far, there has been a dearth of studies on active learning employing game elements or gamification strategies in the area of forecasting. Therefore, this study aims to examine the potential of gamification to improve students' learning outcomes in a context of a forecasting course.

\section{F-LauReL ${ }^{x p}$ description}

F-LauReL ${ }^{x p}$ is designed as a complementary teaching tool in the context of forecasting techniques course, using gamification. F-LauReL ${ }^{\mathrm{xp}}$ is named after Forecasting and "LauReL", a plant that was used as aliment for an ancient Greek priest in order to say oracles and wise advice. The goal of this platform was to engage students into a forecasting techniques course, to improve their learning outcomes, disseminate milestones of forecasting's research and consequently advance students' forecasting skills.

\subsection{F-LauReL ${ }^{x p}$ architecture}

F-LauReL ${ }^{\mathrm{xp}}$ is a web-based modular platform, easily accessible with a browser. Since it is publicly available, a user may navigate through F-LauReL ${ }^{\mathrm{xp}}$ and find information about forecasting aspects and the gamified applications with respective instructions. FLauReL ${ }^{\mathrm{xp}}$ consists of three web-based gamified applications named: Horses for Courses, JudgeIt and Metrics to Escape respectively, as depicted in Figure 1. These applications are independent of each other they have different interfaces and databases, and they are hosted in F-LauReL ${ }^{\mathrm{xp}}$ platform. F-LauReL ${ }^{\mathrm{xp}}$ also has a pivot leader board of participants and statistics about its gamified applications for registered users.

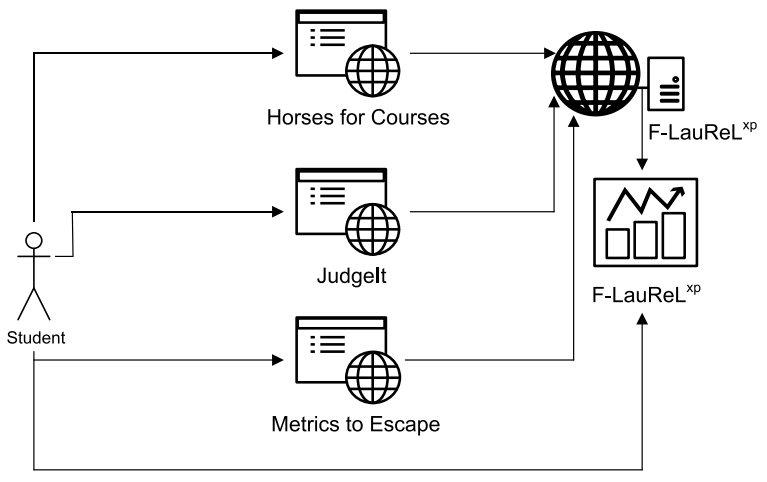

Figure 1. F-LauReL ${ }^{\mathrm{xp}}$ architecture

\subsection{F-LauReL ${ }^{x p}$ components design}

Guidelines for the design of F-LauReL ${ }^{\mathrm{xp}}$ and its components: Horses for Courses, JudgeIt and Metrics to Escape, were derived from the literature and were divided into two main directions: (1) the efficient use gamification elements in learning $[11,12,44,17,38$, $27,28,31,36,13]$ and (2) the design and development gamified applications [45, 34, 24].

Regarding the use of gamified strategies in education, the most commonly used and assessed game elements in reviewed studies so far, are: points, levels, achievements and leader boards [18]. Given that, all three F-LauReL ${ }^{\mathrm{xp}}$ 's gamified applications embody these game elements, in order to invoke to students the willingness of reward, status, and competition [8]. Additionally, each of the three gamified applications incorporates one or more game mechanisms, such as meaningful storyline, time constraints and challenges $[24,45,4]$. More precisely, Table 1 indicates the included game elements and mechanisms per gamified application and the respective purpose served in the context of a forecasting course.

Since the gamified applications: Horses for Courses, JudgeIt and Metrics to Escape were implemented by the authors of this study exclusively for the teaching needs of a forecasting course, we considered the methods and design principles presented in the studies of $[45,35]$, as design guidelines. So, user-friendliness and clear players' guidance [24] determined our design decisions and all F-LauReL ${ }^{\mathrm{xp}}$ 's components have similar user interfaces, in order to keep their aesthetic connection. From a usability point of view, FLauReL ${ }^{\mathrm{xp}}$ 's gamified applications are fully accessible to registered users, with a browser (a free unity-plugin is required for Metrics to Escape). Each application requires registration with an email and a password of users' choice in order to save the progress of every user. 
Table 1. Integration of game elements in FLauReL ${ }^{x p}$ and their aims

\begin{tabular}{|c|c|c|c|}
\hline $\begin{array}{l}\text { Game } \\
\text { Elements }\end{array}$ & $\begin{array}{l}\text { Horses for } \\
\text { Courses }\end{array}$ & JudgeIt & $\begin{array}{l}\text { Metrics to } \\
\text { Escape }\end{array}$ \\
\hline Points & $\begin{array}{l}\text { Correctly } \\
\text { applying } \\
\text { the method } \\
\text { selection } \\
\text { protocol \& } \\
\text { replying to } \\
\text { challenges }\end{array}$ & $\begin{array}{l}\text { Identifying } \\
\text { bias } \\
\text { categories } \\
\text { based on } \\
\text { video } \\
\text { examples }\end{array}$ & $\begin{array}{l}\text { Indicating } \\
\text { metrics } \\
\text { advantage } \\
\text { s and } \\
\text { disadvanta } \\
\text { ges }\end{array}$ \\
\hline Levels & \multicolumn{3}{|c|}{$\begin{array}{l}\text { Students are aware of their progress, via } \\
\text { suitable labels and feel well guided }\end{array}$} \\
\hline $\begin{array}{l}\text { Challenges / } \\
\text { Achievement }\end{array}$ & \multicolumn{3}{|c|}{$\begin{array}{l}\text { Students are motivated to apply the } \\
\text { gained knowledge from the lecture in } \\
\text { the most suitable way, looking for ways } \\
\text { to maximize points gained in every level }\end{array}$} \\
\hline Leader board & \multicolumn{3}{|c|}{ Increase competition among students } \\
\hline $\begin{array}{l}\text { Meaningful } \\
\text { story }\end{array}$ & - & $\begin{array}{l}\text { Students } \\
\text { are } \\
\text { explorers, } \\
\text { who want } \\
\text { to reach a } \\
\text { goal, not } \\
\text { only learn }\end{array}$ & $\begin{array}{l}\text { Students } \\
\text { are } \\
\text { prisoners, } \\
\text { who want } \\
\text { to escape } \\
\text { not only } \\
\text { learn }\end{array}$ \\
\hline $\begin{array}{l}\text { Time } \\
\text { Constraint }\end{array}$ & \multicolumn{2}{|r|}{0} & $\begin{array}{l}\text { Students } \\
\text { are more } \\
\text { challenged } \\
\text { to find } \\
\text { clues and } \\
\text { escape }\end{array}$ \\
\hline
\end{tabular}

A brief description of gamified applications can be seen below:

Horses for Courses. This application aims to disseminate the method selection protocols for fastmoving and intermittent demand time series [37]. Students choose the most appropriate forecasting method based on different conditions and data at each level, getting points according to their choices. Instructions for each level are available to students. A new challenge rises at each level, enforcing the student to apply the knowledge of method selection rules, and improve their performance [7], in order to conquer a leader board position.

JudgeIt. This application targets to communicate heuristics and biases that have great impact on judgmental forecasting [43]. Students participate in a meaningful story, where they become travelers in order to explore different destinations related to heuristics and biases. Travelers aim to gain points by identifying the respective biases of animated examples. Useful video and pictures puzzle and challenge them, whilst instructions guide them to collect points and useful elements, which form their score on the final leader board.
Metrics to Escape. Forecasting accuracy is the subject of this application, which aims to point out the advantages and disadvantages of different accuracy metrics and the usefulness of a new standard accuracy measure [23]. Students become prisoners who are looking for clues regarding statistical metrics, answer questions and solve riddles about metrics characteristics. Then students have to combine these clues in order to discover the formula of the new proposed measure and to escape a 3D virtual room. Students target should be to both escape on time and collect points to reach a good position in the leader board.

\subsection{F-LauReL ${ }^{\mathrm{xp}}$ components implementation}

For the implementation, web technologies were used. More precisely, Javascript, ASP.NET and Unity were used in front-end developing, while PHP with MySQL data-base and VB. NET or C\# with MS-SQL database were used in the back-end.

\section{Experiment Description and Assessment}

\subsection{Participants}

F-LauReL ${ }^{\mathrm{xp}}$ 's gamified applications were launched to students in different semesters. Hence, the experiments for the evaluation of the first gamified application: Horses for courses took place in spring semester 2015 and 2016 to 49 and 60 undergraduate students respectively and fall semester 2015 to 37 MBA students, whilst for the rest applications evaluations took place in spring semester 2016 to 58 and 57 undergraduate students. All experiments were conducted in the context of forecasting techniques course, delivered in the Electrical and Computer Engineering School of the National Technical University of Athens in a total sample of 261 students.

\subsection{Experimental design}

The experimental design was followed strictly, independently of the gamified application, the semester or the level of studies. Students had the same background, without any prior knowledge of the respective field, and their participation in each experiment was optional. However, they were aware of the incentive, which was a 0.5 out of 10 grades for each experiment condition (including control), instead of a respective equivalent exercise in the final examination of the course. 
The respective incentive was a mechanism to motivate students to participate in the experiments. However, every student could receive the highest grade by completing successfully an extra equivalent exercise, equally difficult to the rest of the exercises in the final examination of the course, having sufficient time. Students, who selected to participate in experiments, were randomly assigned to one of the four groups: Group Control, Group Read, Group Play and Group Read\&Play. In order to avoid recruitment bias, there was no difference in incentives among the different groups that the students were randomly assigned to. On top of this, the impact on learning outcomes of the different treatments is examined based on participants performance in an evaluation form, which was the obligatory last task for all participants in our experimental design.

Table 2, illustrates the experimental setup for the evaluation. Initially, all students attended a lecture for 15 minutes, during which the main conclusions of the respective research were presented. Then, they were randomly assigned to one of the groups, represented in Table 2. Each group had 15 minutes to fulfill each one of the tasks assigned to them. More precisely, the Group Control did not have any additional tasks to complete, Group Read had to read the paper for 15 minutes, Group Play had 15 minutes available to make a full round in the respective gamified application passing through all the levels and reach the leader board of the respective gamified application (named thenceforth as task play). Group Read\&Play had 30 minutes to fulfill the task read and then the task play. Since Group Read\&Play had different time, it should not be compared directly to the other groups. Finally, all groups had to complete an on-line evaluation form with 30 equivalent questions about the respective researches' findings within 15 minutes.

\section{Table 2. Design of the evaluation experiment}

\begin{tabular}{|c|c|c|c|c|}
\hline $\begin{array}{c}\text { Task } \\
\text { Description }\end{array}$ & $\begin{array}{c}\text { Group } \\
\text { Control }\end{array}$ & $\begin{array}{c}\text { Group } \\
\text { Read }\end{array}$ & $\begin{array}{c}\text { Group } \\
\text { Play }\end{array}$ & $\begin{array}{c}\text { Group } \\
\text { Read\&Play }\end{array}$ \\
\hline $\begin{array}{c}\text { Attend } \\
\text { Lecture (15 } \\
\text { minutes) }\end{array}$ & $\checkmark$ & $\checkmark$ & $\checkmark$ & $\checkmark$ \\
\hline $\begin{array}{c}\text { Read the } \\
\text { paper (15 } \\
\text { minutes) }\end{array}$ & & $\checkmark$ & & $\checkmark$ \\
\hline $\begin{array}{c}\text { Play (15 } \\
\text { minutes) }\end{array}$ & & & $\checkmark$ & $\checkmark$ \\
\hline $\begin{array}{c}\text { Evaluation } \\
\text { Form (15 } \\
\text { minutes) }\end{array}$ & $\checkmark$ & $\checkmark$ & $\checkmark$ & $\checkmark$ \\
\hline
\end{tabular}

The experimental design for each gamified application had a different lecture and on-line evaluation based on the related forecasting research that the experiment examined. For example, for Horses for Courses' experiment, lecture and evaluation form's content was constructed according to study [37]. Every evaluation form was composed of 30 questions of the same type. Students' performance was calculated as the sum of right answers of the respective evaluation form (normalized to have 100 as maximum value) for each experiment of each gamified application. During the experiment, every task had a strict duration, clear instructions and no extra advice was given. Students were not allowed to collaborate or look for information online while completing each of the tasks.

\subsection{Results of experiment}

The analysis of results was conducted in three steps. Firstly, due to the small sample size, we investigated median instead of mean values of students' performances per group and experiment, received from the assessment of the evaluation forms. Table 3 presents students' performance results, the number of students per experiment and their percentages in each group. Additionally, pairwise nonparametric tests were conducted, with a confidence interval equal to $95 \%$, concluding that groups populations means rank are different in most of the cases.

In this direction, we investigated the percentage differences between median performances of experimental groups and the respective control group per gamified application and semester. Table 4 depicts the respective percentage improvement or decrease for each gamified application and semester. In most cases the median performances of experimental groups outperform the Group Control's median performances but still there are few special cases. Particularly, Group Play composed of undergraduate students, noted the higher median performances of all other treatments, independently of the gamified application or semester. However, this did not apply in the Horses for Courses experiment to MBA students, where the Group Play reached the second highest position. In this experiment, Group Read\&Play noticed the highest median performance and the treatment of reading the paper and use the respective gamified application noticed the highest improvement equal to $90 \%$ compared to the improvements in all experiments. In general, the median performances of Group Read\&Play vary between the second and the third position in the rest of the experiments. Even though, the same treatment provoked a marginally decrease in students' 
performance, compared to respective control group, in Metrics to Escape's experiment.

Table 3. Median performances of students

\begin{tabular}{|c|c|c|c|c|}
\hline 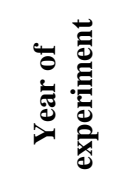 & 氖. & 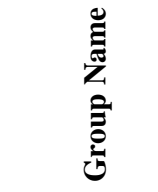 & 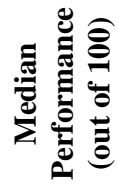 & 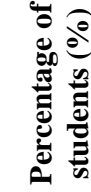 \\
\hline \multirow{4}{*}{ 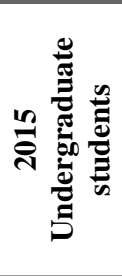 } & \multirow{4}{*}{$\begin{array}{c}\text { Horses for } \\
\text { Course } \\
(\mathrm{n}=49)\end{array}$} & $\begin{array}{l}\text { Group } \\
\text { Control }\end{array}$ & 40.33 & 16.33 \\
\hline & & $\begin{array}{l}\text { Group } \\
\text { Read }\end{array}$ & 53.23 & 28.57 \\
\hline & & Group Play & 70.97 & 24.49 \\
\hline & & $\begin{array}{l}\text { Group } \\
\text { Read\&Play }\end{array}$ & 67.74 & 30.61 \\
\hline \multirow{4}{*}{ 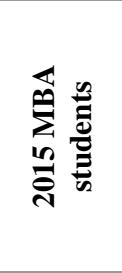 } & \multirow{4}{*}{$\begin{array}{c}\text { Horses for } \\
\text { Course } \\
(\mathrm{n}=37)\end{array}$} & $\begin{array}{l}\text { Group } \\
\text { Control }\end{array}$ & 31.25 & 27.03 \\
\hline & & $\begin{array}{l}\text { Group } \\
\text { Read }\end{array}$ & 37.50 & 24.32 \\
\hline & & Group Play & 51.56 & 21.62 \\
\hline & & $\begin{array}{l}\text { Group } \\
\text { Read\&Play }\end{array}$ & 59.38 & 27.03 \\
\hline \multirow{7}{*}{ 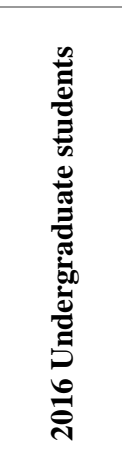 } & \multirow{4}{*}{$\begin{array}{c}\text { Horses for } \\
\text { Course } \\
(\mathrm{n}=60)\end{array}$} & $\begin{array}{l}\text { Group } \\
\text { Control }\end{array}$ & 43.75 & 25.00 \\
\hline & & $\begin{array}{l}\text { Group } \\
\text { Read }\end{array}$ & 62.50 & 21.67 \\
\hline & & Group Play & 70.31 & 30.00 \\
\hline & & $\begin{array}{l}\text { Group } \\
\text { Read\&Play }\end{array}$ & 59.38 & 23.33 \\
\hline & \multirow{3}{*}{$\begin{array}{l}\text { JudgeIt } \\
(\mathrm{n}=58)\end{array}$} & $\begin{array}{l}\text { Group } \\
\text { Control }\end{array}$ & 36.67 & 29.31 \\
\hline & & $\begin{array}{l}\text { Group } \\
\text { Read }\end{array}$ & 33.33 & 24.14 \\
\hline & & Group Play & 56.67 & 22.41 \\
\hline
\end{tabular}

\begin{tabular}{|c|c|c|c|}
\hline & $\begin{array}{l}\text { Group } \\
\text { Read\&Play }\end{array}$ & 53.33 & 24.14 \\
\hline \multirow{4}{*}{$\begin{array}{c}\text { Metrics to } \\
\text { Escape } \\
(\mathrm{n}=57)\end{array}$} & $\begin{array}{l}\text { Group } \\
\text { Control }\end{array}$ & 54.84 & 24.56 \\
\hline & $\begin{array}{l}\text { Group } \\
\text { Read }\end{array}$ & 45.16 & 22.81 \\
\hline & Group Play & 56.45 & 31.58 \\
\hline & $\begin{array}{l}\text { Group } \\
\text { Read\&Play }\end{array}$ & 53.23 & 21.05 \\
\hline
\end{tabular}

Concerning the groups that did not experience the gamified applications, the Group Read can be found inbetween as well, performing better than Group Control, only in Horses for Courses experiments and without having the highest performance in any experiment. Group Control had the lowest median performances for the experiments of Horses for Courses, as it was expected. Nevertheless, this is not the case for JudgeIt and Metrics to Escape's experiments. In JudgeIt's experiment, Group Read has the lowest median performances of the other treatment and control groups. Based on these results, the treatment of reading the paper about the heuristics and biases in judgmental forecasting, under these experimental conditions, seems to lightly puzzle students, presenting slightly lower median performance than the Group Control. In Metrics to Escape's experiment, Group Control has the second highest median performance and the median performances of all the other groups present moderate differences. This can be justified by the fact that the gamified application Metrics to Escape is related with forecasting accuracy metrics. Since there are courses in Electrical and Computer Engineering School relevant with this topic, probably, treatments' effect is limited in this experiment because of students' prior knowledge.

Table 4. Median performance's improvement of treatment groups compared to control.

\begin{tabular}{|c|c|c|r|r|r|}
\hline \multicolumn{6}{|c|}{ Median Performance Improvement (\%) of Treatment Groups compared to control } \\
\hline \multirow{2}{*}{ Experiment } & Year of Experiment & $\begin{array}{c}\text { Group } \\
\text { Control }\end{array}$ & Group Read & Group Play & $\begin{array}{c}\text { Group } \\
\text { Read\&Play }\end{array}$ \\
\hline \multirow{2}{*}{$\begin{array}{c}\text { Horses for } \\
\text { Courses }\end{array}$} & 2015 UG students & - & $31.99 \%$ & $76.00 \%$ & $67.99 \%$ \\
\cline { 2 - 7 } & 2015 MBA students & - & $20.00 \%$ & $65.00 \%$ & $90.00 \%$ \\
\cline { 2 - 7 } & 2016 UG students & - & $42.86 \%$ & $60.71 \%$ & $35.71 \%$ \\
\hline JudgeIt & 2016 UG students & - & $-9.09 \%$ & $54.55 \%$ & $45.45 \%$ \\
\hline Metrics to Escape & 2016 UG students & - & $-17.65 \%$ & $2.94 \%$ & $-2.94 \%$ \\
\hline UG = Undergraduate & \multicolumn{5}{|l}{} \\
\hline
\end{tabular}

Secondly, we gathered data of students' performances from all the experiments, maintaining the same segmentation of treatment groups. Hence, the new aggregated groups: Group Control, Group Read, Group Play and Group Read\&Play consist of undergraduate and MBA students, who experienced the 
same treatment regardless the semester of application and the gamified application per se. Figure 3 illustrates the distribution of students' performances for the aggregated control and treatment groups, in percentiles with box-plot diagrams. Students' performances are symbolized with different shapes, in order to represent the performances of different gamified application's experiments. For example, the filled circle represents the performances of students who participated in Horses for Courses experiment independently of the semester of application or participants' level of studies, for all treatment groups.

Students' Performances for all Gamified Applications per Treatment Game - Horses For Courses $\Delta$ Judgelt $n$ Metrics to Escape

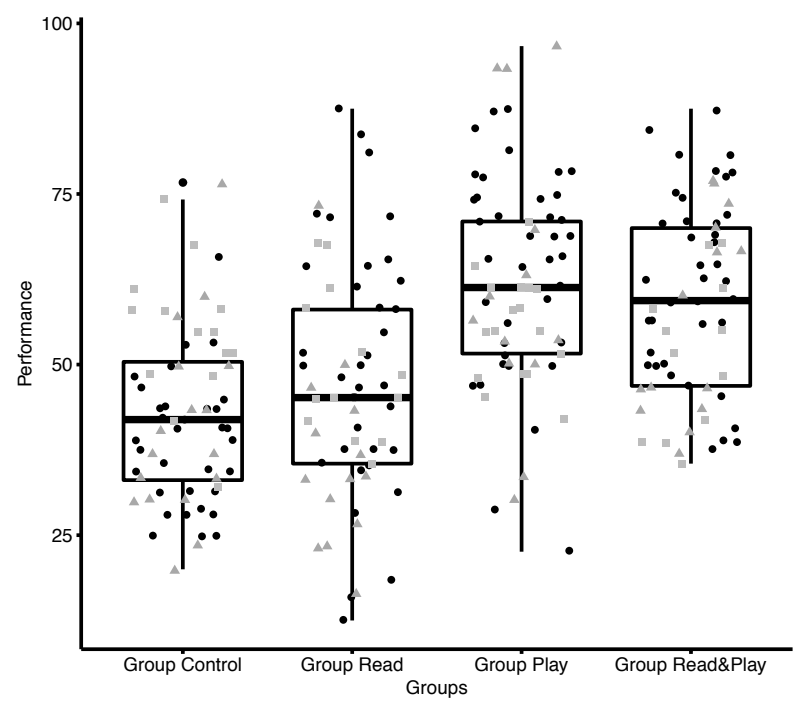

Figure 2. Performances of all groups and gamified applications

The aggregated groups: Group Control, Group Read, Group Play and Group Read\&Play are composed of 64, 63, 69 and 65 students and their median performances are equal to $41.94,45.16,61.29$ and 65.00 out of 100 , respectively. In this regard, all treatments improved students' performances compared to control group. Aggregated Group Play surpassed all the other groups, presenting an improvement regarding median values of performances, equal to $46.15 \%$. Aggregated Group Read\&Play and Aggregated Group Read follow, increasing the median students' performances by $46.15 \%$ and $7.37 \%$ respectively, regarding the median performance of the aggregated Group Control. Furthermore, we conducted nonparametric paired Wilcoxon Signed Rank test, with a confidence interval equal to $95 \%$, in order to test the null hypothesis of zero median difference between pairs of observations. Results of pairwise comparisons between groups are presented in Table 4. Null hypothesis is rejected for all combinations apart from the pairs: Group Control - Group Read and Group Play - Group Read\&Play. Given these results, participation in F-LauReL ${ }^{x p}$ 's gamified applications has significant impact on students' performance.

\section{Table 5. Comparison between groups of all treatments and gamified applications}

\begin{tabular}{|c|c|c|c|}
\hline \multicolumn{2}{|c|}{ Groups Description } & \multicolumn{2}{c|}{$\begin{array}{c}\text { Comparison between } \\
\text { performances }\end{array}$} \\
\hline $\begin{array}{c}\text { Group } \\
\text { Control }\end{array}$ & Group Read & $\mathrm{W}=1660$ & $\mathrm{p}=0.114$ \\
\hline $\begin{array}{c}\text { Group } \\
\text { Control }\end{array}$ & Group Play & $\mathrm{W}=631.5$ & $\mathrm{p}<0.001$ \\
\hline $\begin{array}{c}\text { Group } \\
\text { Control }\end{array}$ & $\begin{array}{c}\text { Group } \\
\text { Read\&Play }\end{array}$ & $\mathrm{W}=740$ & $\mathrm{P}<0.001$ \\
\hline $\begin{array}{c}\text { Group } \\
\text { Read }\end{array}$ & Group Play & $\mathrm{W}=964.5$ & $\mathrm{p}<0.001$ \\
\hline $\begin{array}{c}\text { Group } \\
\text { Read }\end{array}$ & $\begin{array}{c}\text { Group } \\
\text { Read\&Play }\end{array}$ & $\mathrm{W}=1113$ & $\mathrm{p}<0.001$ \\
\hline $\begin{array}{c}\text { Group } \\
\text { Play }\end{array}$ & $\begin{array}{c}\text { Group } \\
\text { Read\&Play }\end{array}$ & $\mathrm{W}=2208$ & $\mathrm{p}=0.276$ \\
\hline
\end{tabular}

In terms of final examination, we gathered data of students' performances from all the experiments and then divided it into two major groups: No F-LauReL ${ }^{\mathrm{xp}}$ group, composed of 127 students who have not been through F-LauReL ${ }^{x p}$ (Group Control and Group Read) and 134 students who used it (Group Play and Group Read\&Play), named F-LauReL ${ }^{\mathrm{xp}}$. We opt for this strategy in order to examine the overall impact of students' participation in F-LauReL ${ }^{\text {xp's gamified }}$ applications in learning outcomes. This strategy is also supported by a number of reasons, such as: the gamified applications were designed under the same guidelines, the evaluation experiments were conducted with the same laboratory settings, and finally, the evaluation forms for each experiment had the same number and type of questions. In the case of Horses for Courses evaluation experiment, the same evaluation form was used independently of the semester of application or participants' level of studies. Figure 3 illustrates the distribution of gathered performances in percentiles with box-plot diagrams. Having larger samples, we conducted paired t-test, with a confidence interval equal to $95 \%$. The null hypothesis of equal differences in means is rejected $(\mathrm{t}=-9.4146, \mathrm{df}=126$, $\mathrm{p}<0.001$ ), while the use of F-LauReL ${ }^{\mathrm{xp}}$ presents an improvement regarding mean values of performances, equal to $34 \%$ approximately.

These gamified applications are proposed as a complementary teaching tool to motivate students and consequently ameliorate their performance. Laboratory settings of this study simulate the future use of these 
gamified applications, without impact on results' validity. Since F-LauReL ${ }^{x p}$ is publicly available, students could use any application out of lectures or in an e-learning environment in the future. However, playing more or looking for further information and applying the gained knowledge in order to achieve a better position in leader board probably would be beneficial for learning outcomes [18], supporting the results of this study.

Students' Performances: Without Gamification vs With Gamification

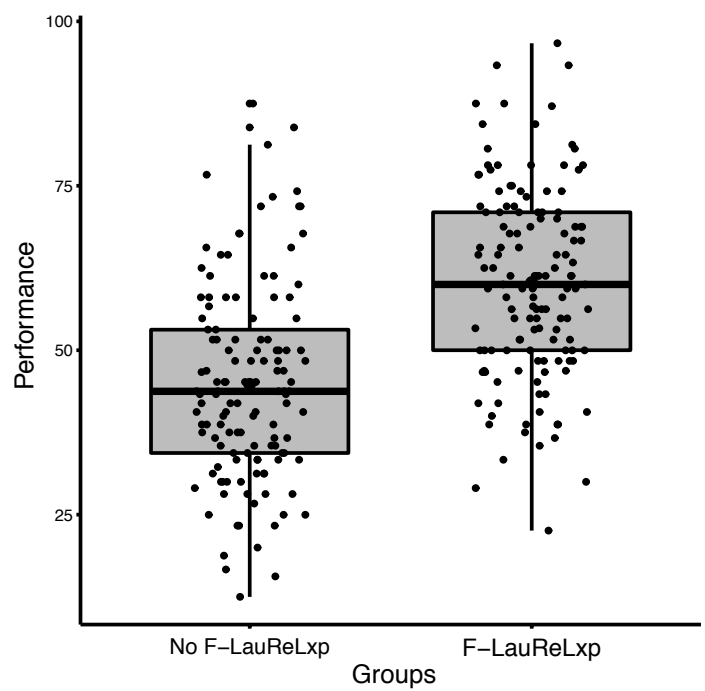

Figure 3. Assessment results of F-LauReL ${ }^{x p}$ application

\section{Conclusions}

Gamification has been progressively used in the context of education, in pursuit of increasing learner motivation and ameliorating learning outcomes. However, thus far there has been a dearth of studies on gamification in the area of learning forecasting, despite the importance of a forecasting course in an economics curriculum [29]. Therefore, this study investigated the effect of gamification on learning in forecasting education by conducting a series of experiments designing and employed three different gamification implementations, called: Horses for Courses, JudgeIt and Metrics to Escape. We conducted a series of experiments to students of a forecasting techniques course $(\mathrm{N}=261)$. In our experiments, we put emphasis on investigating the impact of different tasks such as: reading, use of gamified applications and their combination in students' performance along with the respective performance of the control group.

The conclusions of our empirical study are in agreement with literature findings about the positive impact of gamification on learning $[11,5,17,27,31$, $40,44]$. Results, using treatment and control groups, advocate that gamification does improve students' performance in special forecasting topics. Particularly, the experience of a gamified implementation instead of traditional teaching techniques (lecture and reading), presents an improvement regarding mean values of performances, equal to $34 \%$ approximately. Secondly, under certain conditions, the use of gamification may have a greater impact than reading or even reading and use a gamified application, as far as forecasting learning is concerned. It could increase students' performance by up to $76 \%$ compared to merely attending a respective lecture. However, results reveal that the effect of the combination of gamification and reading a respective article regarding the percentage improvement on students' comprehension varies from $2.94 \%$ up to $90 \%$, under certain conditions.

In these terms, F-LauReL ${ }^{x p}$ can be suggested as a useful complementary educational tool which contributes to the improvement of learning outcomes and comprehension of specific forecasting topics. Nevertheless, further investigation of the effects of individual game elements in a forecasting techniques course is proposed. In this direction, a wider sample, composed of students and practitioners, could be an interesting addendum to compare gamification's impact on different populations as well.

Further extension of F-LauReL ${ }^{\mathrm{xp}}$ could be the integration of a superforecasters' project [42], which challenge participants to insert their forecasts in real world problems. The evaluation of participants' forecasts could be another evaluation method of students' performance and an assessment of gamification's impact on forecasting accuracy. Finally, F-LauReL ${ }^{x p}$ should host more applications to teach additional forecasting aspects. The integration of the "Learning to forecast Experiment" [21, 2, 3] could add important value to F-LauReL ${ }^{\mathrm{xp}}$, by helping collect data about students' interactions to predict the asset price under changeable conditions in an artificial and gamified market.

Some limitations should be acknowledged in relation to the results of our study. As for the experimental design, even though students' performances of Group Read\&Play were compared directly to other groups' performances, without having the same overall treatment's duration, the result can still show that gamification can positively influence the learning outcomes. Another limitation of our study is that no discussion is presented about the difficulty of alternative exercises in final examination compared to participate in the experiments of gamification and receive the incentive. For example: how much time it would cost students to finish the exercises, which may 
affect the test takers' performance in answering other questions. In this regard, it can be argued maybe these alternative questions are harder to respond correctly than attempting the gamification applications. It is complex to compare these tasks due to different nature and subjective evaluation of them, whereas future experimental design should be benefit from considering it and eliminate potential bias.

\section{Acknowledgements}

This work has been supported by Business Finland (5479/31/2017 and 40009/16) and participating partners, Satakunnan korkeakoulusäätiö and its collaborators, and Academy of Finland (Center of Excellence in Game Culture Studies). A work-inprogress version of this work was presented in International GamiFIN Conference 2018.

\section{References}

[1] M. D. Albritton and P. R. McMullen, Classroom integration of statistics and management science via forecasting," Decision Sciences Journal of Innovative Education, vol. 4, no. 2, pp. 331 \{336, 2006.

[2] T. Assenza, T. Bao, C. Hommes, and D. Massaro, "Experiments on expectations in macroeconomics and finance," in Experiments in macroeconomics, pp. 11-70, Emerald Group Publishing Limited, 2014.

[3] T. Bao, C. Hommes, and T. Makarewicz, "Bubble formation and (in) efficient markets in learning-to-forecast and optimise experiments," The Economic Journal, vol. 127, no. $605,2017$.

[4] A. K. B. G. Bharathi, A. Singh, C. S. Tucker, and H. B. Nembhard, "Knowledge discovery of game design features by mining user-generated feedback," Computers in Human Behavior, vol. 60, pp.361-371, 2016.

[5] P. Buckley and E. Doyle, "Gamification and student motivation," Interactive Learning Environments, vol. 24, no. 6, pp. 1162-1175, 2016.

[6] P. Buckley and E. Doyle, "Individualising gamification: An investigation of the impact of learning styles and personality traits on the efficacy of gamification using a prediction market,"Computers \& Education, vol. 106, pp. 43-55, 2017.

[7] P. Buckley, J. Garvey, and F. McGrath, "A case study on using prediction markets as a rich environment for active learning," Computers \& Education, vol. 56, no. 2, pp. 418428, 2011.
[8] I. Bunchball, "Gamification 101: An introduction to the use of game dynamics to influence behavior," White paper, vol. 9,2010 .

[9] S. Chu, Some initiatives in a business forecasting course," Journal of Statistics Education, vol. 15, no. 2, 2007.

[10] C. W. Craighead, "Right on target for time-series forecasting," Decision Sciences Journal of Innovative Education, vol. 2, no. 2, pp. 207-212, 2004.

[11] L. da Rocha Seixas, A. S. Gomes, and I. J. de Melo Filho, "Effectiveness of gamification in the engagement of students," Computers in Human Behavior, vol. 58, pp. 48 63, 2016

[12] S. Deterding, D. Dixon, R. Khaled, and L. Nacke, "From game design elements to gamefulness: Defining "gamification"," in Proceedings of the 15th International Academic MindTrek Conference:Envisioning Future Media Environments, MindTrek '11, (New York, NY, USA), pp. 915, ACM, 2011.

[13] A. DomíNguez, J. Saenz-De-Navarrete, L. De- Marcos, L. FernáNdez-Sanz, C. PagéS, and J.-J. MartíNez - Herrálz, "Gamifying learning experiences: Practical implications and outcomes," Computers \& Education, vol. 63, pp. 380-392, 2013

[14] R. Gapp and R. Fisher, "Undergraduate management students perceptions of what makes a successful virtual group," Education+ training, vol. 54, no. 2/3, pp. 167-179, 2012.

[15] L. Gardner, "Using a spreadsheet for active learning projects in operations management," INFORMS Transactions on Education, vol. 8, no. 2, pp. 75-88, 2008.

[16] S. Gavirneni, "Teaching the subjective aspect of forecasting through the use of basketball scores," Decision Sciences Journal of Innovative Education, vol. 6, no. 1, pp. 187-195, 2008.

[17] J. Hamari, D. J. Shernoff, E. Rowe, B. Coller, J. AsbellClarke, and T. Edwards, "Challenging games help students learn: An empirical study on engagement, flow and immersion in game-basedlearning," Computers in Human Behavior, vol. 54, pp. 170-179, 2016.

[18] J. Hamari, J. Koivisto, and H. Sarsa, "Does gamification work?-a literature review of empirical studies on gamification," in System Sciences (HICSS), 2014 47th Hawaii International Conference on, pp. 3025-3034, IEEE, 2014.

[19] J. Hanke, "Forecasting in business schools: A follow-up survey," International Journal of Forecasting, vol. 5, no. 2, pp. $259-262,1989$.

[20] M. D. Hanus and J. Fox, "Assessing the effects of gamification in the classroom: A longitudinal study on 
intrinsic motivation, social comparison, satisfaction, effort, and academic performance," Computers \& Education, vol. 80, pp. $152-161,2015$.

[21] C. Hommes, "The heterogeneous expectations hypothesis: Some evidence from the lab," Journal of Economic dynamics and control, vol. 35, no. 1, pp. 1-24, 2011.

[22] K. Huotari and J. Hamari, "A definition for gamification: anchoring gamification in the service marketing literature," Electronic Markets, vol. 27, no. 1, pp. 21-31, 2017.

[23] R. J. Hyndman and A. B. Koehler, "Another look at measures of forecast accuracy," International journal of forecasting, vol. 22, no. 4, pp. 679-688, 2006.

[24] K. M. Kapp, The gamification of learning and instruction fieldbook: Ideas into practice. JohnWiley \& Sons, 2013.

[25] J. Kasurinen and A. Knutas, "Publication trends in gamification: A systematic mapping study," Computer Science Review, vol. 27, pp. 33 - 44, 2018.

[26] J. Koivisto and J. Hamari, "The rise of motivational information systems: A review of gamification research", Working paper, 2017.

[27] M. -S. Kuo and T.-Y. Chuang, "How gamification motivates visits and engagement for online academic dissemination an empirical study," Computers in Human Behavior, vol. 55, pp. $16-27,2016$.

[28] E. Kyewski and N. C. Krmer, "To gamify or not to gamify? an experimental field study of the influence of badges on motivation, activity, and performance in an online learning course," Computers \& Education, vol. 118, pp. 25 37, 2018.

[29] D. G. Loomis and J. E. Cox Jr, "Principles for teaching economic forecasting," International Review of Economics Education, vol. 2, no. 1, pp. 69-79, 2003.

[30] T. E. Love and D. K. Hildebrand, "Statistics education and the making statistics more effective in schools of business conferences," The American Statistician, vol. 56, no. 2 , pp. $107-112,2002$

[31] C. Maican, R. Lixandroiu, and C. Constantin, "Interactivia.ro a study of a gamification framework using zero-cost tools," Computers in Human Behavior, vol. 61, pp. $186-197,2016$.

[32] J. Majuri, J. Koivisto and J. Hamari, "Gamification of education and learning: A review of empirical literature," in Proceedings of the 2nd International GamiFIN conference, Pori, Finland,2018
[33] S. Makridakis, S. C. Wheelwright, and R. J. Hyndman, Forecasting methods and applications. John wiley \& sons, 2008 .

[34] B. Morschheuser, J. Hamari, J. Koivisto, and A. Maedche, "Gamified crowdsourcing: Conceptualization, literature review, and future agenda," International Journal of Human-Computer Studies,vol. 106, pp. 26-43, 2017.

[35] B. Morschheuser, L. Hassan, K. Werder, and J. Hamari, "How to design gamification? a method for engineering gamified software," Information and Software Technology, 2017.

[36] O. Pedreira, F. Garca, N. Brisaboa, and M. Piattini, "Gamification in software engineering a systematic mapping," Information and Software Technology, vol. 57, pp. $157-168,2015$.

[37] F. Petropoulos, S. Makridakis, V. Assimakopoulos, and K. Nikolopoulos, "horses for courses in demand forecasting," European Journal of Operational Research, vol. 237, no. 1, pp. $152-163,2014$

[38] J. Sánchez - Martín, M. A. Dávila -Acedo, et al., "Just a game? gamifying a general science class at university: Collaborative and competitive work implications," Thinking Skills and Creativity, vol. 26, pp. 51-59, 2017.

[39] K. Seaborn and D. I. Fels, "Gamification in theory and action: A survey," International Journal of human-computer studies, vol. 74, pp. 14-31, 2015.

[40] J. Simões, R. D. Redondo, and A. F. Vilas, "A social gamification framework for a k-6 learning platform," Computers in Human Behavior, vol. 29, no. 2, pp. 345-353, 2013.

[41] B. R. Snider and J. B. Eliasson, "Beat the instructor: An introductory forecasting game," Decision Sciences Journal of Innovative Education, vol. 11, no. 2, pp. 147-157, 2013.

[42] P. E. Tetlock and D. Gardner, Superforecasting: The art and science of prediction. Random House, 2016.

[43] A. Tversky and D. Kahneman, "Judgment under uncertainty: Heuristics and biases," science, vol. 185, no. 4157, pp. 1124-1131, 1974.

[44] I. Yildirim, "The effects of gamification-based teaching practices on student achievement and students' attitudes toward lessons," The Internet and Higher Education, vol. 33, pp. $86-92,2017$

[45] G. Zichermann and C. Cunningham, Gamification by design: Implementing game mechanics in web and mobile apps. ” O’Reilly Media, Inc.”, 2011. 